\title{
Clinicopathological analysis of AUB in perimenopausal and postmenopausal women in cancer care centre: special reference to carcinoma endometrium
}

\author{
Varsha Deshmukh*, Afsha Suboohi, Archana Rathod, Jyoti Kodgire
}

Department of Gynaecology, GMC and Cancer Hospital, Aurangabad, Maharashtra, India

Received: 03 May 2021

Accepted: 29 May 2021

\section{*Correspondence:}

Dr. Varsha Deshmukh,

E-mail: deshmukhvl@yahoo.com

Copyright: () the author(s), publisher and licensee Medip Academy. This is an open-access article distributed under the terms of the Creative Commons Attribution Non-Commercial License, which permits unrestricted non-commercial use, distribution, and reproduction in any medium, provided the original work is properly cited.

\begin{abstract}
Background: Abnormal uterine bleeding (AUB) may be defined as any variation from normal menstrual cycle including alteration in its regularity, frequency, duration of flow and amount of blood loss. Postmenopausal bleeding is a danger sign for malignancy. The study aimed to study the histopathology spectrum of hysterectomy specimens and bleeding patterns in perimenopausal women and postmenopausal women.

Methods: It was a retrospective observational study done at Government Medical College and Cancer Hospital, Aurangabad (MS) from January 2017 to January 2021. Total sample size was 100 women. Perimenopausal and postmenopausal women undergoing hysterectomy were analysed for the age, parity, etieology, histology and the malignant changes.

Results: 22 cases of AUB were observed in the age group of less than 40 years. $56 \%$ cases presented with heavy menstrual bleeding 58\% cases had prolonged menstrual bleeding. 36\% cases had endometrial cause (harmonal disturbances), $12 \%$ had endometrial polyp and 35 cases out of 100 had endometrial carcinoma. Both type 1 and type 2 cases of carcinoma endometrium are seen in this study.

Conclusions: Excessive uterine bleeding is a common gynaecological problem in all age groups with significant patient morbidity. The spectrum of endometrial lesions seen in AUB and cancer cases shows that the histopathological examination of endometrium is gold standard diagnostic tool in evaluation of AUB and postmenopausal bleeding and there is an age specific association of endometrial lesions.
\end{abstract}

Keywords: AUB, Cancer endometrium, Histopathology of endometrium

\section{INTRODUCTION}

Abnormal uterine bleeding (AUB) is defined as any variation from the normal menstrual cycle, including changes in regularity and frequency of menses, in duration of flow, or in amount of blood loss. ${ }^{1}$ More than $70 \%$ of all gynecological consultations in the peri and postmenopausal age group is due to abnormal bleeding complaint. ${ }^{2}$ AUB is further categorised which is based on volume of menstruation, regularity, frequency and duration related to reproductive status. In 2011, the FIGO classification system (PALM-COEIN) was published in order to standardize terminology, diagnosis and investigations in women presenting with AUB. ${ }^{3}$ Excessive bleeding or intermenstrual spotting and postmenopausal bleeding are common conditions affecting women at all ages.

It is important to reach correct clinical diagnosis and identify the causative factor and treat it adequately. We conducted this study with the aim to study the histopathology spectrum of hysterectomy specimens and 
bleeding patterns in perimenopausal women and postmenopausal women.

\section{METHODS}

It was a retrospective observational study done at Government Medical College and Cancer Hospital, Aurangabad (MS) from January 2017 to January 2021. Total sample size was 100 women.

\section{Inclusion criteria}

Perimenopausal women age group of 40 years and above till 1 year beyond menopause who were admitted with complaints of AUB and underwent hysterectomy and women presenting with postmenopausal bleeding and underwent hysterectomy were included in the study.

\section{Exclusion criteria}

Women who were less than 40 years of age undergoing medical treatment of AUB were excluded from the study.

After obtaining informed consent from selected patients, the relevant data such as age, parity, menstrual symptoms (past and present menstrual history), and medical/surgical history was noted from the case records. General, systemic and gynaecological examination and other associated findings in clinical examination were recorded. Following history and examination, investigations including $\mathrm{CBC}$, coagulation profile, thyroid function test, LFT, RFT were noted. After all required workup clinical diagnosis and allocation to PALM COEIN was done. Besides a thorough history taking and examination in all these women, ultrasonographic evaluation was done to assess uterus (size, polyp, fibroid, adenomyosis, and endometrial thickness) and ovarian status and recorded. The clinical presentations and ultrasonographic findings were noted. MRI was done in cases of cancer endometrium. Medical management was started to those appropriate. Hysterectomy was done in indicated cases. Histopathologic report of hysterectomy specimens including endometrial, myometrial, and cervical findings were noted. Data were expressed as number, percentage and results were analyzed using Graph Pad Software, Inc; Version 3.1

\section{RESULTS}

Table 1 shows the relation between age and parity, maximum number of cases (40) were in the age group of 41 - 50 years with parity of 3 and higher. As evident in the study incidence of AUB among perimenopausal age group was maximum in multiparous women. Grandmultiparous women were $30 \%$ in the study. Postmenopausal women were $38 \%$ in the study.

Table 2 shows 56 women had heavy menstrual bleeding and 58 women presented with prolonged menstrual bleeding. 34 women presented with postmenopausal bleeding. Dysmenorrhoea was also seen frequently as associated symptom.

Table 1: Distribution of cases according to age and parity $(n=100)$.

\begin{tabular}{|lllllll|}
\hline Parity & $\begin{array}{l}\text { Age }<\mathbf{4 0} \\
\text { years }\end{array}$ & $\begin{array}{l}\mathbf{4 1 - 5 0} \\
\text { years }\end{array}$ & $\begin{array}{l}\mathbf{5 1 - 6 0} \\
\text { years }\end{array}$ & $\begin{array}{l}\mathbf{7} \mathbf{6 0} \\
\text { years }\end{array}$ & $\mathbf{N}=\mathbf{1 0 0}$ & $\%$ \\
\hline $\mathbf{1}$ & 3 & 2 & 0 & 2 & 7 & 7 \\
\hline $\mathbf{2}$ & 10 & 13 & 7 & 2 & 32 & 32 \\
\hline $\mathbf{3}$ & 6 & 11 & 7 & 7 & 31 & 31 \\
\hline $\mathbf{4}$ & 3 & 6 & 1 & 8 & 18 & 18 \\
\hline $\mathbf{> 5}$ & 0 & 8 & 1 & 3 & 12 & 12 \\
\hline
\end{tabular}

Table 2: Distribution of cases according to clinical presentation ( $\mathrm{n}=100)$.

\begin{tabular}{|lll|}
\hline Menstrual disturbances & $\mathbf{N}=\mathbf{1 0 0}$ & $\%$ \\
\hline Heavy menstrual bleeding & 56 & 56 \\
\hline Irregular menstrual bleeding & 17 & 17 \\
\hline Frequent menstrual bleeding & 35 & 35 \\
\hline Prolonged menstrual bleeding & 58 & 58 \\
\hline Dysmenorrhoea & 26 & 26 \\
\hline Postmenopausal bleeding & 34 & 34 \\
\hline
\end{tabular}

Note: Combination of two or three menstrual disturbances were seen in one patient.

Table 3: Distribution of cases according to PALMCOEIN Classification $(n=100)$ on hysterectomy specimen.

\begin{tabular}{|lll|}
\hline PALM-COIEN & $\mathbf{N = 1 0 0}$ & $\%$ \\
\hline AUB-E & 36 & 36 \\
\hline AUB-M & 35 & 35 \\
\hline AUB-L & 20 & 20 \\
\hline AUB-A & 22 & 22 \\
\hline AUB-P & 12 & 12 \\
\hline AUB-O & 10 & 10 \\
\hline AUB-N & 2 & 2 \\
\hline
\end{tabular}

Note: Combination of two or three pathologies were seen in one patient.

Table 3 shows that the most common lesion seen was endometrial pathology (proliferative endometrium in 25 patients, secretary endometrium in 11 patients) followed by cancer of endometrium in 34 cases. Fibroid was seen in 20 cases and adenomyosis was seen in 22 cases. 2 cases presented with myometrial hypertrophy and AV Malformation.

Table 4 shows 65 patients were non-malignant and had proliferative $(25 \%)$, secretary $(11 \%)$ and atrophic endometrium. Foreign body granulomatous reaction was seen in 2 patients. 35 patients had cancer endometrium. Out of which 29 had adenocarcinoma (endometroid) type and the rest had very rare types of cancer endometrium.

Table 5 shows that $45.7 \%$ patients presented with stage 1 A. $17.5 \%$ patients were seen in stage $1 \mathrm{~B}$ and $3 \mathrm{~A}$. No 
patients were operated in stage 4 . Only $2.8 \%$ presented in stage $3 \mathrm{C}$.

Table 4: Different histological subtypes of endometrial reports in non-malignant and malignant cases in hysterectomy specimens.

\begin{tabular}{|lll|}
\hline Histological subtypes & $\mathbf{N}=\mathbf{1 0 0}$ & \% \\
\hline Proliferative & 25 & 25 \\
\hline Secretory & 11 & 11 \\
\hline $\begin{array}{l}\text { Simple hyperplasia without } \\
\text { atypia }\end{array}$ & 8 & 8 \\
\hline Atrophic endometrium & 4 & 4 \\
\hline $\begin{array}{l}\text { Foreign body } \\
\text { granulomatous reaction }\end{array}$ & 2 & 2 \\
\hline Disordered proliferative & 1 & 1 \\
\hline Malignant subtypes & 29 & 29 \\
\hline Adenocarcinoma & 2 & 2 \\
\hline Clear cell carcinoma & 1 & 1 \\
\hline Adenosquamous carcinoma & 1 & 1 \\
\hline $\begin{array}{l}\text { Stromal tumor of } \\
\text { endometrium }\end{array}$ & 1 & 1 \\
\hline Mixed Mullerian tumour & 1 & 5 \\
\hline $\begin{array}{l}\text { Carcinosarcoma of } \\
\text { endometrium }\end{array}$ & 2 & \\
\hline
\end{tabular}

Note: More than one histological subtypes co-existed in one patient.

Table 5: Distribution of cancer endometrium cases.

\begin{tabular}{|llllll|}
\hline Stage & $\begin{array}{l}\text { FIGO } \\
\text { Grade }\end{array}$ & $\begin{array}{l}\text { Grade } \\
\mathbf{2}\end{array}$ & Grade 3 & $\mathbf{N = 3 5}$ & $\%$ \\
\hline 1A & 6 & 1 & & 16 & 45.7 \\
\hline 1B & & 3 & 1 & 6 & 17.1 \\
\hline II & 4 & & 3 & 8.5 \\
\hline IIIA & 5 & 2 & 6 & 17.1 \\
\hline IIIB & & & 4 & 3 & 8.5 \\
\hline IIIC & & & 1 & 1 & 2.8 \\
\hline
\end{tabular}

\section{DISCUSSION}

Abnormal uterine bleeding (AUB) is one of the most common and significant presenting complaint in the gynaecology clinic. It causes considerable morbidity and affects the patient significantly. ${ }^{4}$ A spectrum of histologic changes are noted in the endometrium in AUB and postmenopausal bleeding which vary according to the age of the patient and includes functional pattern or organic lesions. Histopathologic study of endometrial tissue is a major diagnostic tool in patients presenting with AUB and to rule out malignancy.

In our study 65 specimens showed benign pathologies while 35 were malignant on evaluation and post hysterectomy. This is because ours is a regional cancer institute. Patients are referred from all over the state whenever malignancy is suspected. Perimenopause is defined by World Health Organisation (WHO) as the 2 to
8 years preceding menopause and the 1 year after the final menses and postmenopausal bleeding is bleeding from the genital tract after 1 year of menopause. ${ }^{5}$ This age group of patients are prone for harmonal disturbances, structural lesions and malignant changes in the endometrium. This is because of the derangement in the structure of the uterus (such as leiomyoma, polyps, adenomyosis, malignancy, or hyperplasia), or disruption of the hypothalamic-pituitaryovarian axis (through ovulatory/endocrine disorders) and some premalignant and malignant changes in this age group. ${ }^{6}$ Clusters of cases in this age group could be due to decreased ovarian function resulting in low estrogen level which can no longer mantain the endometrial growth Table 1.

In our study 40 patients presented in the perimenopausal age group and 38 patients presented with postmenopausal bleeding. Present study significantly shows that the incidence of menstrual disorders increases with advancing age. We observed that age was as an important factor governing the histological progression. Age was directly associated with increasing aggressiveness of lesions since more progressive lesions were found in peri and postmenopausal age group as compared to reproductive age group. Multiparous and grandmultiparous (30\%) women were commonly seen in our study. This finding is compatible with the studies carried out by Bolde et al. ${ }^{7}$

In Table 2, Our study showed that among the study population (post hysterectomy patients) $56 \%$ women presented with heavy menstrual bleeding, 58\% with prolonged menstrual flow, $35 \%$ with frequent bleeding, $26 \%$ with pain in abdomen and 34\%) with postmenopausal bleeding. The hypothalamic-pituitary-ovarian axis fails to develop the necessary hormonal feedback to result in ovulation and a subsequently stable endometrium in perimenopausal age group of patients. The clinical manifestations are irregular menstrual cycle, irregular menstruation, and even amenorrheoa. ${ }^{8}$ Previous study suggested that endometrial causes of bleeding are associated with increased surface area and brittleness of the blood vessels, resulting in endovascular blood flow increase to overcome platelet aggregation. This may be due to polyps, fibroids, adenomyosis or hyperplasia which is seen frequently in this age group of patients. ${ }^{9}$ These findings are similar to the study done by Bolde et al. ${ }^{7}$

Table 3 shows the distribution of patients according to the PALM-COIEN classification proposed by FIGO in 2011 which divided AUB into structural and nonstructural cause in our study AUB-E and AUB-O was seen most commonly as a eiteological cause $(46 \%)$ cases which signifies the underlying harmonal imbalance in our patients. ${ }^{10}$ Consistent with previous studies, a changing menstrual cycle is the most important hemorrhage pattern for those with AUB-O and AUB-E. The reason for this is the ovulatory dysfunction caused by the malfunction of the hypothalamic-pituitary-ovarian axis. ${ }^{11}$ In the absence of ovulation, a corpus luteum does not develop and the ovary fails to secrete progesterone. This results in continual 
endometrial proliferation without progesterone withdrawal-induced shedding and bleeding, which manifests as a changed menstrual pattern.

AUB-M is seen in $35 \%$ cases in our study. Every postmenopausal woman with bleeding undergoes an endometrial sampling to rule out malignancy. The frequency of endometrial carcinoma was high in our study (35\%). Type 1 endometrial carcinoma was seen in majority (29 cases) while Type 2 in 6 participants which is considered to be more aggressive $(17.1 \%, 6 / 35)$. It was seen most commonly in post-menopausal age group $(95 \%)$ followed by perimenopausal ( 3 cases). Type 1 is estrogenrelated endometrioid carcinoma. Type 2 is nonestrogenrelated, non-endometrioid carcinoma. Studies suggest that the most common type of endometrial carcinoma is endometrioid adenocarcinoma, which is composed of malignant glandular epithelial elements with an admixture of squamous metaplasia. It develops from endometrial hyperplasia in the setting of excess estrogen exposure. ${ }^{12}$

AUB-L was seen in 20 cases and AUB-P was in 12 cases. Uterine fibroids is a common disease in women, with a high incidence. ${ }^{12}$ The symptoms of AUB are more related to the location and size of the myoma, and the incidence of AUB-L is closely related to the increase in endometrial surface area because of fibroids. ${ }^{13}$ Myoma and endometrial causes of bleeding are associated with increased surface area and brittleness of the blood vessels, resulting in endovascular blood flow.

Approximately $10 \%$ to $40 \%$ of women with AUB have endometrial polyps, and the severity of the symptoms was not related to the diameter, location, and number of polyps. This study found that AUB caused by endometrial polyps accounted for $12 \%$ of cases, slightly lower than that reported by Clark et al, that is, AUB caused by AUB-P was $20 \% \sim 30 \%{ }^{8}$

AUB-A was seen in $22 \%$ cases in this study. It was the most common disorder associated in AUB with endometrial disorders, fibroids and even malignancy cases. The main bleeding pattern is a prolonged duration of flow, accounting for $58 \%$ of cases in our study, followed by HMB. It may be associated with increased uterine surface area because of increased uterine volume. ${ }^{14}$ AUB$\mathrm{N}$ was seen in 2 cases. They were myometrial hypertrophy and AV malformation.

Table 4 shows different subtypes of endometrial histopathological features in cases with excessive bleeding. In AUB cases, endometrial hyperplasia, proliferative, secretary and disordered proliferative patterns were seen. 4 cases show atrophic endometrium and 2 cases showed foreign body granulomatous reaction in the endometrium. Copper $\mathrm{T}$ insertion for prolong periods can lead to the foreign body granulomatous reaction in the endometrium. However Bhatta et al reported a lower value of $29.16 \% .^{15}$ Proliferative endometrium was also a predominant finding in less than
40 years $(35.2 \%)$ in our study which is comparable to the study done by Doraiswami et al who reported 33.3\%. ${ }^{16}$

Out of 100 cases, 29 cases presented with type 1 endometroid lesion and 6 cases presented with type 2 nonendometroid lesions in malignant cases. Type I tumors, which account for $80 \%$ of endometrial carcinomas, are associated with a hyperplastic endometrium, and area associated with unopposed estrogen stimulation. They are of endometrioid histology, are estrogen responsive, and have a favorable prognosis. Type II endometrial carcinomas, by contrast, often arise from an atrophic endometrium. They include papillary serous carcinomas and clear cell carcinomas, are estrogen independent, and have a less favorable prognosis. Endometrial sarcomas are much less common. Subtypes of sarcomas include carcinosarcomas, endometrial stromal tumors, leiomyosarcomas, and adenosarcomas. ${ }^{17}$ In our study rare type 2 subtypes of cancer endometrium were seen. This is due to the regional cancer institute status, we get a huge referral for cancer endometrium. Hence the proportion of cancer cases is huge in our study.

Table 5 shows the distribution of cancer endometrium cases in our study at presentation. We found 16 cases $(45.7 \%)$ in stage 1 A with 6 cases in grade 1 cells. This has extremely good prognosis. Most women, over 70\%, have FIGO stage I cancer, which has the best prognosis. ${ }^{18}$ Stage III cancers has a worse prognosis, but these are relatively rare, occurring in only $13 \%$ of cases. In our study we had 10 cases of cancer endometrium in stage 3. Most of them were associated with grade 3 types of cells. There were no stage 4 cases in the study as they become inoperable and have a less survival period. 3 patients presented in stage 2 . All the cases underwent Wertheim's hysterectomy with lymph node dissection. IHC was done in all type 2 cases. They received chemoradiation and are on regular followup. Type 1 cases belonging to stage 1A are kept on follow-up. Chemotherapy, radiotherapy, harmonal therapy and targeted therapies are the various options of treatment in this cases. ${ }^{19}$

\section{CONCLUSION}

Excessive uterine bleeding is a common gynaecological problem in all age groups with significant patient morbidity. USG, endometrial biopsy and histopathological report are the diagnostic tool. A structured approach to establishing the cause using the FIGO PALM-COEIN classification system will facilitate accurate diagnosis and inform treatment options. With the marked increase in endometrial cancer, the authors would encourage all gynaecologists to continue to excise their clinical judgement for those women aged $>40$ years with HMB and do endometrial biopsy to rule out malignancy.

Funding: No funding sources

Conflict of interest: None declared

Ethical approval: The study was approved by the Institutional Ethics Committee 


\section{REFERENCES}

1. Fraser IS, Critchley HO, Munro MG, Broder M. Can we achieve international agreement on terminologies and definitions used to describe abnormalities of menstrual bleeding? Hum Reprod. 2007;22(3):63543.

2. Talukdar B, Mahela S. Abnormal uterine bleeding in perimenopausal women: correlation with sonographic findings and histopathological examination of hysterectomy specimens. J Midlife Health. 2016;7(2):73-7.

3. Singh S, Best C, Dunn S, Leyland N, Wolfman WL, Wolfman W, et al. Abnormal uterine bleeding in premenopausal women. J Obstetr Gynaecol Canada. 2013;35(5):473-5.

4. Puvitha RD, Shruthi EMS, Shylaja S. Histopathological study of endometrium in abnormal uterine bleeding an experience in a tertiary care centre of Rural South India. National J Basic Med Sci. 2017;8(1):32-8.

5. Deka RR, Saikia T, Handique A, Sonowal B. Histopathological spectrum of endometrial changes in women presenting with abnormal uterine bleeding with special reference to endometrial malignancies:a two years hospital based study. Annals Applied Biosci. 2016;3(2):44-9.

6. Cheong Y, Cameron IT, Critchley HOD. Abnormal uterine bleeding. Br Med Bull. 2017;123(1):103-14.

7. Bolde SA, Pudale SS, Pandit GA, Matkari PP. Histopathological study of endometrium in cases of abnormal uterine bleeding. Int $\mathrm{J}$ Res Med Sci. 2017;26:2(4):1378-81.

8. Clark TJ, Stevenson H. Endometrial polyps and abnormal uterine bleeding (AUB-P): what is the relationship, how are they diagnosed and how are they treated? Best Pract Res Clin Obstet Gynaecol. 2017;40:89-104.

9. Bittencourt CA, Simões DSR, Bernardo WM. Accuracy of saline contrast sonohysterography in detection of endometrial polyps and submucosal leiomyomas in women of reproductive age with abnormal uterine bleeding: systematic review and meta-analysis. Ultrasound Obstet Gynecol. 2017;50:32-9.
10. Munro MG, Critchley HO, Broder MS, Fraser IS. FIGO working Group on menstrual disorder. FIGO classification system (PALM-COEIN) for causes of abnormal uterine bleeding in non-gravid women of reproductive age. Int J Gynaecol Obstet. 2011;113:313.

11. Hauk L. American College of Obstetricians and Gynecologists. ACOG releases guidelines on management of abnormal uterine bleeding associated with ovulatory dysfunction. Am Fam Physician. 2014;89:987-8.

12. Zaino RJ, Kurman R, Herbold D. The significance of squamous differentiation in endometrial carcinoma: data from a Gynecologic Oncology Group study. Cancer. 1991;68(10):2293-302.

13. Güzel AI, Akselim B, Erkılınç S. Risk factors for adenomyosis, leiomyoma and concurrent adenomyosis and leiomyoma. J Obstet Gynaecol Res. 2015;41:932-7.

14. Taran FA, Weaver AL, Coddington CC. Characteristics indicating adenomyosis coexisting with leiomyomas: a case-control study. Hum Reprod. 2010;25:1177-82.

15. Bhatta S, Sinha AK. Histopathological study of endometrium in abnormal uterine bleeding. $\mathrm{J}$ pathol Nepal. 2012;2(4):297-300.

16. Doraiswami S, Johnson T, Rao S, Rajkumar A, Vijayaraghavan J, Panicker VK. Study of endometrial pathology in abnormal uterine bleeding. J Obstet Gynaecol India. 2011;61(4):426-30.

17. Colgan TJ, McLachlin CM. In Comprehensive Cytopathology. Available at 2008 https: //www.sciencedirect.com/science/article/pii/B978141 6042082100107. Accessed on 12 January 2021.

18. Burke WM, Orr J, Leitao M, Salom E, Gehrig P, Olawaiye $\mathrm{AB}$, et al. Endometrial cancer: a review and current management strategies: part I. Gynecologic Oncology. 2009;134(2):385-92.

19. Hoffman BL, Schorge JO, Schaffer JI, Halvorson LM, Bradshaw KD, Cunningham FG. Endometrial Cancer. Williams Gynecology (2 $2^{\text {nd }}$ edition). McGraw-Hill. 2012:833.

Cite this article as: Deshmukh V, Suboohi A,

Rathod A, Kodgire J. Clinicopathological analysis of AUB in perimenopausal and postmenopausal women in cancer care centre: special reference to carcinoma endometrium. Int J Reprod Contracept Obstet Gynecol 2021;10:2739-43. 